\title{
ENGLISH STUDIES IN AN AFRIKAANS UNIVERSITY*
}

University studies in English are a comparatively recent introduction at English universities. Cambridge, for instance, first established a Chair of English in 1911. The comparable dates for certain other subjects are as follows: Mechanics, 1875; Physics, 1871; Zoology, 1866. Cambridge was, in fact, the last of the senior British universities to establish a Chair of English. Edinburgh, apparently, was the first, with its Chair of Belles-Lettres which was an off-shoot of the Department of Logic. The need for this Chair arose partly from the replacement of Latin as the medium of instruction by English. Nowadays one often finds that the practical study of English as a means of communication is rejected on traditional grounds as unacademic. It is rather disconcerting to find that for the first 135 years of its existence the oldest University Department of English devoted its energies at least partly to what we would call "Practical English."

When eventually Chairs of English came to be established in other British Universities, they were originally occupied by men trained in other disciplines, mainly the Classics, Theology, History and Philosophy. ${ }^{1}$ ) It is interesting to note that Cape Town, the oldest South African university, had a single professor for both the Classics and English until 1860; from 1860 to 1875 English was taught by the Professor of Physics and later on by the Professor of Philosophy.

"The early university syllabuses for Honours degrees in English Literature were made to appear academically respectable through the pretence that English was a dead language. As the reading of literature was not thought to be difficult in itself, difficulties appear to have fabricated, so much so that one might call these early courses

* Inaugural address, 1st May, 1964. 
'punitive'. Philological studies (the 'Language' side of 'English Language and Literature') predominated. Students read a good deal in the old Germanic languages, such as Old Norse and Anglo-Saxon. 'English Literature' was presumed to have come to an end in $1830 \ldots{ }^{2}$ )

The courses in literature were generally of the "survey" kind and students were required to display some knowledge of all periods of English literature. Obviously this was second-hand knowledge, because it is impossible to read, let alone study, all the important works concerned in three or four academic years. The aim was, as Saintsbury put it, "first to construct, and then to fill in, a map of literature".3) This is the tradition in which most of us were originally trained. It will be observed that its connection with literature as such is almost incidental. Basically it is a branch of history, and one could presumably complete the course without actually losing one's pristine innocence of contact with literary texts.

In the early twenties of the present century radical changes in the aims and methods of English studies were introduced, first at Cambridge and later at other universities. Critics such as Richards, Empson and Leavis came to insist on the close reading of a relatively limited number of texts with a view to fostering the development of genuine literary taste. They refused "to be seduced into the by-paths of social history, biography and philology, as irrelevant to the functions of pure criticism".4) Today this transmutation of English studies has been completed and hardly any English Department in the English-speaking world remains unaffected by it. ${ }^{5}$ ) There are, in fact, signs of a reaction against the so-called "New Establishment" in criticism.

An interesting, if somewhat confusing modern tendency, which is particularly noticeable in the U.S.A., but which one also finds in this country, is to divorce linguistic studies from the various separate "language" departments and to set up an autonomous Department of General Linguistics. In South Africa this tendency has 
been strengthened by the neglect of synchronic linguistic studies in Departments of English.

Like members of other post-colonial societies, South Africans are much preoccupied with their cultural roots and have an inordinate longing for stable traditions. Any departure from tradition, real or imaginary, is highly suspect. If there were an immutable tradition in English studies, the present discussion might well have been dispensed with. As I have shown, there is no such stable tradition. In addition, the linguistic and cross-cultural problems involved in teaching English to Afrikaansspeaking students give rise to a situation that is totally different from that obtaining at British and American universities. It is not unique, however. In fact, England itself was a bilingual country until the last half of the fourteenth century, with French occupying a position similar to that of English in S.A. at the end of the nineteenth century. John of Trevisa, writing in 1385, tells us about the change to mother-tongue instruction in the schools:

"This manner (i.e., teaching Latin to English children through medium of French) was much used before the first plague (1349) and has since then been somewhat changed. For John Cornwall, a master of grammar, changed the teaching in grammar school ... from French to English ... so that now, the year of our Lord a thousand three hundred four score and five, of the second King Richard after the Conquest the ninth, children in all the grammar schools of England leave French and learn in English ... and have thereby the advantage... that they learn their grammar in less time... The disadvantage is that children in the grammar school know no more French than their left heel."

In the contemporary world, English is studied as a foreign language in many countries. As a second language it is taught in considerable number of so-called emergent states, where the problems to be faced are generally greater than ours, mainly because of the greater degree of linguistic and cultural disparity and the presumably 
lower standard of general education. Even a casual read ing of the relevant technical journals convinces one of the magnitude of the problems involved. To put is bluntly, too few of the students who present themselves at the University know enough English to profit from a course in English literature. With regard to this country, the President of the English Academy of Southern Africa has recently put the matter as follows:

"Students from Afrikaans-medium schools ... are, in fact, not sufficiently literate to study literature profitably; it is impossible to teach literature to illiterates to people who have not the necessary grasp of syntax, grammar and idiom".6) While one might not agree with the tone and some of the implications of Prof. KnowlesWilliams's statement, one has to admit that there is a certain amount of truth in it. Unless the University teacher of literature is prepared to go in for unashamed shadow-boxing, his concern is with total meaning, and in particular with those shades and nuances of thought and feeling which distinguish good writing from mediocre. Of course it is possible to extract one or more compo nents from literature and to base a course on these. One could treat literature as history or philosophy or sociology; an ingenious soul might even use literary texts as a source of culinary or sartorial edification, but he would obviously not be teaching literature but a travesty of it.

In the serious study of literature the synoptic approach seems to me to be wholly inappropriate. If literature is to communicate the quality of experience it has to be specific. It is concerned not so much with the intellectual content of words, events or situations, but rather with their impact on the sensibility of the poet and with his ability to communicate this total experience to the reader. It celebrates the fullness of Creation and dwells lovingly upon whatever "stands in God's unchanging eye," on every beauty that "He fathers-forth whose beauty is past change." Literature, then, concerns itself with meaning beyond the merely intellectual, with suggesting, evoking, communicating the unsayable - al 
though, it must be admitted that much of contemporary literature seems to be suggestively preoccupied with the unspeakable.

E. M. Forster has written with much insight about the "prophetic" function of the artist - prophetic not in the sense of foretelling the future but of interpreting what is. One is also reminded of the lines by W. B. Yeats:

"God guard me from those thoughts men think In the mind alone;

He that sings a lasting song,

Thinks in the marrow-bone."

Obviously a fairly mature and sophisticated command of the language is required for the comprehension of what is really worthwhile in literature. The choice before an English Department in an Afrikaans University is either to exclude three-quarters of its prospective students, or to undertake the teaching of the language as such by way of preparation for the literary and linguistic studies which would be its normal field in an English university.

In the time at my disposal I can do no more than to indicate briefly the basic problem that this involves. An exhaustive survey of the twenty centuries or so of foreign language teaching in the history of our culture would require several weighty tomes. It is probably true that more progress in the scientific study of language teaching has been made in the past two or three decades than in the previous millennium. This does not mean that the desired scientific rigour and precision have penetrated into our classrooms. Much of what is popularly believed and even some of what is being taught about language and language learning is not scientific, not even based on common sense. It is, shall we say, more in the nature of folklore, hallowed, in a sense, by the patina of the ages, but undeniably a curious conglomeration of fact and fancy, cult, cant and folkbelief, of social attitudes and inherited pedagogical pedantries, and sometimes also of deliberate obfuscation and obscurantism. It seems to be a deeply ingrained pattern in our culture 
that we tend to become obsessed with a shaving of the truth, and the thinner the shaving the more exquisite the resulting ideological agony.

The natural method of learning a language is by prolonged random exposure to the language in situational contexts - that is how one learns one's mother-tongue. Any method that subjects the student to experience of the language in use will work, even if such exposure is purely fortuitous. The language teacher's problem is essentially that of improving on nature. The time at his disposal is too limited for him to wait for nature to take its course.

The traditional solution is to use a codification of structure and usage, such as a systematic grammar sets out to provide. This does indeed provide a short-cut, but not to be desired destination. It will not, by itself, lead to spontaneous aural-oral proficiency. Another problem is that the academic mind seems to be irresistibly attracted by the niceties and intricacies of scientific method. There tends to be so much debate about the precise nature of the short-cut that its practical purpose is entirely forgotten.

The current dogma is that a foreign language can best be learned from an instructor trained in applied linguistics and using scientifically selected materials and electronic equipment of the kind installed in so-called "language laboratories". Obviously extensive reading can augment the experience of the language provided in this way. Mastery of a language is a complex skill, based on a set of deeply ingrained habits; or, in current transAtlantic gobbledygook: "points and patterns of facilitation"; or again, in Dutch psychological parlance: "systems of valencies". The essential point is that constant reinforcement of the recently acquired patterns of linguistic behaviour is required to counter the persistent inhibitory interference of the prior speech habits of the mothertongue. It would seem, however, that there is a "point of no return" beyond which the loss from non-use of the language is relatively slow, and the recovery of the skills 
so lost fairly easy. There also appears to be a saturation point beyond which drill as such becomes prohibitively subject to a process of diminishing returns.

Although the system of valencies through which the basic structural mechanism of the language is operated may short-circuit the cognitive processes, remedial measures must at times include attention pointers to provide a conscious focus because many residual errors seem to result from a lack of awareness on the part of the student that his speech habits differ from the approved model. He is, in fact, so hardened in sin that he really does not notice his errors. One thinks of the Australian who insists that he says Austrilian like everybody else - or the South African who, for city, says [sati:], just like the B.B.C. Recognition of the error will not necessarily eliminate it, however. Practice is still required to consolidate the gain.

Another problem is that many of the difficulties and errors with which we are plagued at this level are not particularly amenable to treatment by massive doses of linguistic drill, because they derive from differences bctween the content structures of the base and target languages. In a certain sense it is at this level that the idiosyncracy of a language is best exemplified. The way in which speakers of a particular language arrest and segment the flux of experience in order to match it with discrete linguistic items and patterns tends to condition the nature of what such speakers perceive, at least in so far as it has a bearing on linguistic meaning. This takes us to a level where the artifact of language shades into the underlying culture - into the way in which the members of the group habitually structure the world of their experience, both intellectually and emotionally. Techniques for dealing with these recalcitrant cross-cultural patterns of meaning require very sophisticated programme design. At the level of near-native proficiency selective drills probably have no edge over random exposure, particularly if the psychological colouring of the two types of activity is taken into account. 
In a community which, by the nature of its circumstances, is forced to try to achieve a high level of bilingualism, velleity appears to be the politician and educational administrator's besetting sin. Real proficiency in a foreign language is such a complex skill that it requires a great deal of effort and extended periods of contact with the language in use. For effective contact, students have to be taken individually or in very small tutorial groups. "Ay, there's the rub". Learning to speak and write a foreign language really well is not the sort of activity a university is really staffed or equipped to undertake, unless much use is made of tutors, student instructors or automated, programmed teaching. It is for the powers that be to decide whether we should cater for the exceptional few who do not need this kind of attention, or whether we should set ourselves the task of teaching the average undergraduate enough English for him to profit from a course in literature. If the latter is their choice, they would have to face the implications of their decision.

The general tendency in the world seems to be to extend university education to ever wider groups of young citizens. In the U.S.A. it is already being said that popular education does not end with a school-leaving certificate, but with a first degree. In Britain the tide is running strongly against the traditional élitist view of university education. To me it seems that, unless we abandon the current South African policy of more or less compulsory bilingualism or, alternatively, feed a larger proportion of the total multi-racial population into the universities, we have no choice but to accept all such students as offer themselves. If we do, the obligation to provide the required grounding in the language and culture cannot be avoided, even if it means that we have to interpose a year of preparatory work between the last year of school and the first year's academic course in English.

Reference has been made to the scientific study of language. To my mind, a university department of English language and literature would be sadly failing in its task if it were to neglect either the diachronic or synchronic 
study of language. We happen to live in a country which is a vast language laboratory, where half-a-dozen languages rub shoulders in our day-to-day affairs and yet we tend to behave as if we were safely ensconced in the sequestered cloisters of the Old World. Part of the blame for the inefficiency of our language teaching must rest squarely on the shoulders of the language departments in our universities. It is natural for an immigrant community to tend to embalm and preserve intact the metropolitan culture from which its own derives. In fact, the professional custodians of such a culture generally prefer to enshrine a historical form of it. At the same time, however, it is obviously the task of the lively intellects which are supposed to foregather at a university to respond to the challenge of their time and circumstances. The neglect of research in comparative linguistics and, in fact, of linguistic research in general, seems to show that we have not yet faced up to the realities of the South African situation.

Thus far we have been concerning ourselves mainly with the utilitarian aspects of English studies; and yet the greater portion of the time in our academic courses is devoted to the study of literature. The era in which we live is highly utilitarian in its outlook and justly critical of pedantry and obscurantism. The claim that a discipline is traditional will not suffice. A university is an enormously expensive institution, and the public which support it feel that they have a right to demand that it perform a useful service to the community. It appears to be incumbent on those of us who teach literature to show cause why our discipline should not be relegated to the status of a superannuated cult or, at best, a harmless pastime, and to affirm the positive values that it entails.

The psychologist, W. M. S. Russel ${ }^{7}$ ) has suggested that "any human society has two general problems; it has to deal with its natural environment, in order to maintain its economy and protect itself from natural catastrophes; but it also has to regulate itself, for the 
maintenance of stability and progress." He then assigns the first function to science and its utilitarian technological off-shoots. Aesthetic factors, he feels, play a central part in the mental health of the community. He rejects the Victorian dichotomy between the aesthetic, on the one hand, and the useful and didactic on the other. Things of beauty are useful to society in direct proportion to their beauty. The need for aesthetic satisfaction is a secondary, but innate and inescapable urge, the frustration of which takes its toll of the personality and even of mental health. It would seem that such faculties as the organism may possess, require to be used and are denied at the owner's peril.

Although this view of art as a form of mental therapy will be unacceptable to many students of aesthetics, it is remarkable how persistent this and similar theories have been, involving, as they do, not only modern writers such as Richards, but reaching back to the very beginnings of literary criticism in ancient Greece.

We have already, in another context, referred to the "celebratory" function of literature - to the fact that it contemplates and recreates the texture of human experience; that it "explores the diversity, complexity and strangeness of that experience ... with a disinterested passion... In literature men look at life with all the vulnerability, honesty and penetration they can command... and dramatize their insights by means of a unique relationship with language". ${ }^{8}$ )

Most of us will be familiar with the Shakespearian passage on the creative imagination:

"The poet's eye, in a fine frenzy rolling,

Doth glance from heaven to earth, from earth to heaven;

And, as imagination bodies forth

The forms of things unknown, the poet's pen

Turns them to shapes, and gives to airy nothing A local habitation and a name."

In his controversial poem, "Ars Poetica", Archibald Macleish makes the point that a poem is an artifact, an 
object of beauty constructed of words; that it should not state, but evoke:

"A poem should be equal to:

Not true

For all the history of grief

An empty doorway and a maple leaf

For love

The leaning grasses and two lights above the sea-

$A$ poem should not mean

But be."

Richard Hoggart gives what is probably a more complete and balanced view of literature when he says: "Literature can never be aesthetically "pure" or abstractly contemplative. There can be no such thing as "abstract" literature ... By its nature - because its medium, language, is used by almost everybody in all sorts of everyday situations, ... it tries both to say and to be ..." ${ }^{18}$ ) Apparently it is the interpretative, "prophetic" function of literature that has the greatest appeal for the maturer, more thoughtful mind. In his old age Yeats gave supreme expression to the consuming intellectual passion of the poet as a seer, as a Tiresias-like figure who is concerned with ultimate truth:

"My temptation is quiet.

Here at life's end

Neither loose imagination,

Nor the mill of the mind

Consuming its rag and bone,

Can make the truth known.

Grant me an old man's frenzy,

Myself must I remake

Till I am Timon and Lear

Or that William Blake

Who beat upon the wall

Till truth obeyed his call..."9)

In "Sailing to Byzantium" he celebrates poetry as one of the "monuments of unageing intellect": 
"An aged man is but a paltry thing,
A tattered coat upon a stick, unless
Soul clap its hands and sing, and louder sins
For every tatter in its mortal dress...
O sages standing in God's holy fire
As in the gold mosaic of a wall
Come from the holy fire, perne in gyre,
And be the singing masters of my soul."

It is by no means my purpose to join the faction fight of the "two cultures". What I wish to assert, is the relevance of literature to our times and circumstances, a claim which is often denied on behalf of the sciences and their brood of technological disciplines. In the words of Steiner "there is demonstably more of insight into the matter of man in Homer, Shakespeare or Dostoevsky than in the entirety of neurology or statistics... It is precisely the 'objectivity', the moral neutrality in which the sciences rejoice and attain their brilliant community of effort, that bars them from final relevance... What light we possess on our essential, inward condition is still gathered by the poet". ${ }^{10}$ )

It is a truism to point out that a great poet creates his own rhetoric and so influences the development of the language in which he writes. Many lines from, for instance, Shakespeare and Wordsworth have been so wholly absorbed into the idiom of the language that only the literary scholar is aware of their origin. The artist's use of his medium leaves an enriching sediment in the general culture of his public. He helps to create a climate of opinion and not only interprets but also conditions the sensibility of his generation. As Steiner succinctly puts it:

"No western eye, since van Gogh, looks on a poplar without observing in it the start of a flame."

Of course, Plato knew about the power of the artist - and disapproved of it; Aristotle and Sir Philip Sidney also knew about it - and approved; Matthew Arnold thought the humanities, especially poetry, the most effective means of educating the whole man; both George 
Eliot and D. H. Lawrence have written convincingly about the power of the novel to inform and educate our sympathetic consciousness and moral receptiveness.

Recent and contemporary English criticism has been much concerned with the question of values in literature. Naturally various points of view have been put forward. They range from outright moralism to the attitude that literature is "merely a game of knowledge". About the fact that the study of great literature makes for intellectual and emotional maturity, there can be no doubt. Reliving the finest thoughts and feelings of some of the choicest spirits in a great culture must of necessity enrich the experience, sharpen the mind and refine the sensibility of the young reader. Nor will the gain be limited to his appreciation of the specific literature he is reading. His studies will add depth to his insight into and edge to his appreciation of all literature, including that of his own culture, and will help him to realize to the full the aesthetic potentialities with which his Creator has endowed him. In prompting the young intellectual to discover his own essential humanity, and to explore - vicariously, by imaginative reconstruction - the widest possible range of human experience, the study of literature serves the cause of true education.

\section{P.U. for C.H.E.}

J. A. Venter.

1) A. C. Partridge in English Studies in Africa, Vol. 1, no. 1.

2) F. P. Gibbon and T. H. Gibbons in College English, Vol. 25, no. 5, Feb., 1964.

3) Partridge, op cit., p. 6

4) Op cit.

5) Cf. G. Watson: The Literary Critics, p. 208.

6) Onderwysblad, March, 1964, p. 473.

7) The Listener, 16/1/64

8) The Times Literary Supplement, July 26, 1963, p. 541.

9) An Acre of Grass.

10) The Times Literary Supplement, July 26, 1963, p. 539. 